\title{
PENYUSUNAN DATABASE ARSITEKTUR NUSANTARA BERBASIS TIPOLOGI ARSITEKTUR DARI PARADIGMA BUDAYA
}

\author{
Ema Yunita T, Abraham M. Ridjal
}

\author{
Universitas Brawijaya
}

ema.yunita@gmail.com

\begin{abstract}
ABSTRAK
Penelitian mengenai arsitektur nusantara saat ini tersebar luas. Perlu upaya untuk menghimpun dan menyatukan hasil-hasil penelitian tersebut agar dapat dimanfaatkan untuk perbaikan negeri. Database Arsitektur Nusantara berisi kejamakan dan kemajemukan ragam arsitektur nusantara merupakan upaya yang strategis bagi kebutuhan penelitian bertema kearifan lokal arsitektur nusantara. Database ini dimanfaatkan dan dikembangkan bersama secara partisipatori dengan media web online. Dasar penyusunan data base adalah perumusan tipologi arsitektur dengan paradigma budaya yaitu: Keperkasaan Masyarakat Megalit, Kewaspadaan Pelestari Lingkungan Hutan, Ketekunan Masyarakat Tani Pedalaman, Keterbukaan Masyarakat Pesisir, dan Kelenturan Masyarakat Dagang, Industri dan Informasi. Variabel amatannya didasarkan pada aspek dan unsur-unsur arstitektural, yang kelengkapannya tergantung ketersediaan data. Jenis data meliputi data deskriptif (tulisan/paparan), gambar 2 dan 3 dimensi, peta-peta, hingga model digital X3D dalam bentuk video. Kelengkapan data ini dapat dikembangkan dan dibangun bersama-sama. Dengan adanya database yang dapat menjadi salah satu bahan rujukan penelitian arsitektur, diharapkan data-data hasil penelitian ini dapat bermanfaat bagi pengembangan pengetahuan yang terkandung dalam arsitektur nusantara sehingga bermanfaat bagi perbaikan negeri ini.
\end{abstract}

Kata kunci: database (data dasar), Arsitektur Nusantara

\section{Pendahuluan}

Duplikasi penelitian / kajian Arsitektur Nusantara terjadi akibat tidak adanya sinergi dan kerjasama di antara para peneliti. Hal ini mempersulit perkembangan sekaligus aplikasi teknologi yang diperoleh dari hasil penelitian / kajian. Data-data dasar Arsitektur Nusantara memiliki banyak kelemahan yang disebabkan oleh beberapa hal, antara lain:

1. Semakin langkanya obyek Arsitektur Nusantara yang dapat dikaji akibat semakin cepatnya 'penggusuran' dan 'penghancuran' artefak Arsitektur Nusantara

2. Rekaman data historis sangat minim, terutama yang tersimpan di kantor-kantor atau lembaga-lembaga pemerintah yang berwenang dan seharusnya berkewajiban mencari dan menyimpan data-data tersebut. Data-data ini umumnya tersebar, dimiliki oleh masing-masing peneliti.

3. Minimnya komunikasi dan hubungan kerjasama antar peneliti sehingga seringkali terjadi duplikasi data dan duplikasi penelitian

4. Tidak adanya data-base Arsitektur Nusantara sebagai hasil inventarisasi dan identifikasi hasil-hasil kajian /penelitian. Data-base ini sangat strategis dalam memberikan informasi dan data mengenai kajian / penelitian Arsitektur Nusantara.

5. Keragaman dan kemajemukan Arsitektur Nusantara luar biasa besar. Dari 
Sabang sampai Merauke; dari Timor sampai Talaud, sekian puluh ribu suku bangsa di Nusantara memiliki keunikan budaya, termasuk arsitekturnya. Mustahil untuk dapat menggali dan mengembangkan kekayaan Arsitektur Nusantara tanpa adanya sinergi antar lembaga, antar peneliti dan antar pihakpihak terkait. Data-base Arsitektur Nusantara yang berbasis web-media dapat menjadi jembatan komunikasi antar pihak-pihak yang memiliki kepedualian terhadap keberlajutan Arsitektur Nusantara.

Data-base Arsitektur Nusantara sangat penting dan sangat diperlukan bagi penelitian dan kajian Arsitektur Nusantara. Dalam rangka menyelamatkan nilai-nilai luhur budaya bangsa di lingkup arsitektur, sekaligus menyelamatkan sisa-sisa artefak Arsitektur Nusantara.

Konservasi bukan sekedar mengawetkan, tetapi lebih lanjut berupaya menggali kandungan keilmuan dari artefak (obyek konservasi) untuk dikembangkan melalui kreativitas dan inovasi sehingga dapat dimanfaatkan untuk kehidupan di masa kini. Tidak hanya di level praksis, tetapi juga di tingkat konsep, teori, sampai filosofi. Dengan demikian kegiatan konservasi tidak hanya berhenti sampai tahap pencapaian target jumlah wisatawan tetapi sampai pada penemuan dan pengembangan keilmuan untuk kehidupan masa kini dan yang akan datang. Pembuatan data-base Arsitektur Nusantara merupakan salah satu upaya untuk mengembangkan keilmuan melalui konservasi artefak atau replikanya.

Publikasi Arsitektur Nusantara saat ini kebanyakan hanya bias menjangkau kalangan akademisi dan juga para peminat arsitektur nusantara khususnya yang jumlahnya tidak seberapa. Hal ini tentu saja berdampak sangat serius, karena kurangnya minat terhadap keilmuan yang terkandung di arsitektur nusantara, terutama bagi generasi muda akan semakin menggerus keberlangsungannya.

Perkembangan dunia informasi digital saat ini telah membawa selera generasi muda bukan lagi dalam hal membaca atau belajar lewat tulisan, akan tetapi penyampaian ide/ gagasan melalui gambar atau 3D interaktif bahkan video lebih mudah untuk menarik minat para generasi muda. Dengan demikian, ketidakberimbangan antara data yang tersedia dengan penyajian yang dilakukan, diharapkan dapat dijembatani dengan baik melalui program ini. Hal ini ditujukan agar generasi muda kita kedepan akan lebih tertarik lagi dalam menggali dan mempelajari keilmuan yang terkandung dalam arsitektur Nusantara yang sudah ada yntyk dikembangkan menjadi lebih baik lagi melalui kreativitas para generasi muda.

\section{Bahan Dan Metode}

\subsection{Tipologi Arsitektur Nusantara}

Arsitektur Nusantara memerlukan paradigma tipologi baru. Berbagai macam pendekatan dapat dilakukan, sejak dari pendekatan historis, arsitektonik sampai pendekatan antropologis. Semuanya sah, karena semua dapat bermanfaat. Tetapi Indonesia membutuhkan kategorisasi yang sesuai dengan tuntutan mempertahankan kesatuan kebudayaannya, agar mengurangi timbulnya segmentasi sosial.

Pendekatan etnografis (arsitektur Jawa Sunda, Bali, dan seterusnya) yang populer di masa lalu, bisa saja memperuncing sukuisme. Pendekatan historis pun bukan tanpa resiko. Pemilahan periode dengan label agama secara sangat halus bisa saja mengkotak-kotakkan pengamat (dan mereka yang mempelajari arsitektur). Istilah arsitektur Cina Perantauan pun dapat saja beresiko menimbulkan kotak segmentasi sosial. Bangsa ini telah nyaris terpecah-belah. Akankah masa lalu dan keadaan 
arsitekturnya di masa kini dipakai untuk mempertajam kepingan-kepingan keterpecahan sosial itu? Betapa makin sulitnya mempertahankan kesatuan bangsa!

Lebih bijak bila kita memakai tipologi yang disusun dengan tujuan memaparkan karakter paling khas dari tiap kelompok kebudayaan-peradaban dengan masing-masing lingkungan alamnya. Hal ini tak mudah, karena harus dikerjakan sambil mengurutkan perkembangan tiap kategori secara historis dan sekaligus menempatkannya pada geografi yang sangat luas dan berkemajemukan tinggi pula. Arsitektur Nusantara dapat kita pilah menurut ciri peradaban dan kebudayaan masyarakatnya. Arsitektur rakyat di Nusantara dilihat sebagai satu kesatuan peradaban dari unsur-unsur kebudayaan, nilainilai, dan sifat-sifat luhur budaya bangsa yang diwariskan secara turun temurun di seluruh ruang budaya Nusantara, sebagai berikut:

- Keperkasaan Penerus Tradisi Batu Besar (misalnya Nias atau Sumba)

- Kewaspadaan Pelestari Hutan (misalnya Mentawai, Dayak, dan Papua)

- Ketekunan Penggalang Pertanian (pertanian dataran rendah dan yang di dataran tinggi seperti Tengger, Kintamani, dan sebagainya)

- Keterbukaan Penjalin Pesisir (misalnya Madura, Using, dan lain-lain)

- Kelenturan dan Kedinamisan Masyarakat Dagang, Industri dan Informasi

Tipologi budaya di atas itu memang normatif, bahkan seolah-olah hanya hendak kembali ke romantisme masa lalu. Tetapi lebih dari sekedar mempelajari arsitektur dari kacamata materialisme pattern atau form language dalam kajian arsitektur yang sangat (atau bahkan terlalu) spesifik, maka sebenarnya di balik kategorisasi itu ada muatan politik kebudayaan, atau dalam istilah almarhum Clifford Geertz: politik makna. Tipologi itu, sejak dari buku "Merah-Putih Arsitektur Nusantara" (2006) terus terang disusun berdasarkan pada suatu tujuan langkah kebudayaan: menjaga kelestarian Indonesia sebagai satu kesatuan wilayah identitas, atau ruang kultural. Bahasa Gus Dur bisa jadi lebih singkat: NKRI, harga mati! Dalam istilah Mpu Tantular: bhineka tunggal ika, tan hana dharma mangrwa (berbeda-beda namun satu, tak ada sikap-perbuatan [dharma] yang mendua; satu upaya bahu membahu untuk tujuan yang diyakini bersama kebaikannya). Bisa jadi, tujuan tadi terlalu subtil atau samar untuk ditangkap yang biasa hanya mempelajari aspek materi arsitektur, sehingga dalam suatu acara bedah buku "Merah-Putih" di atas, ada seorang pembahas yang melihat bagian kajian tipologi dalam buku tersebut tidak berhubungan dengan bagian kajian filosofi di depannya. Padahal, paradigma atas sesuatu pasti berlandaskan sebuah bidang-pijak filosofis.

\subsection{Data Base Berbasis Masyarakat (PAPAN)}

Data base partisipatif pada dasarnya adalah penyusunan informasi yang sepenuhnya melibatkan masyarakat. Masyarakat penghimpun informasi (perguruan tinggi, lembaga penelitian, lembaga swadaya masyarakat, dsb) atau masyarakat di suatu suatu "teritori informasi" adalah yang paling mengenal secara mendalam data Arsitektur Nusantara pada lingkungannya. Karenanya, merekalah sebenarnya yang mampu menggambarkan secara detil dan akurat mengenai sejarah, tradisi dan pandangan hidupnya, juga orientasi dan harapan masyarakat lokalnya (di tempat atau lokalitas masing-masing lembaga terbut) di masa mendatang. Data base berbasis masyarakat dalam hal ini adalah upaya membantu masyarakat dalam membuat data base untuk menggambarkan pemahamannya atas tipologi Arsitektur Nusantara.

Dengan demikian, tentu saja data base partisipatif berbeda dengan kegiatan dan struktur data base yang dilakukan pemerintah. Meski keduanya sama-sama 
menggunakan teknik data base yang standar, namun aplikasi dan pelaku teknik-teknik tersebut tetap berbeda.

\subsection{Tahap Pelaksanaan Kegiatan}

Tahap-tahap kegiatan yang dilakukan meliputi:

- Langkah 1: Penyusunan model teoritik

- Langkah 2: Persiapan data dasar dan peralatannya.

1. Data yang sudah terkumpul diolah untuk mengkategorikan menjadi lebih rapi dan terinci.

2. Kegiatan dilakukan bertahap menurut geografis Indonesia: Pulau Jawa, Kalimantan, Sumatera, Sulawesi, dan Papua.

3. Melakukan sharing dan diskusi dengan pihak-pihak terkait (praktisi dan akademisi)

- Langkah 4: Pengolahan data serta Pengembangan struktur informasi data base, menyangkut potensi budaya, kebudayaan lokal, dan objek material (artefak arsitektural) serta interaksi sosio-kultural yang terkait dengan identifikasi, pelestarian dan pengembangan Arsitektur Nusantara dgn metoda partisipatorik.

1. Penentuan variabel penelitian ini tergantung dari kelengkapan data yang sudah tersedia. Jika perlu dilakukan pengamatan primer untuk melengkapi data.

2. Pengolahan data sesuai kategorisasi yang ditetapan dalam penyusunan tipologi.

3. Meng-input data tersebut ke dalam database yang sudah disiapkan. Pemilihan dan penentuan kata kunci sangat penting agar database dapat dengan mudah dipergunakan oleh semua pihak yang membutuhkan.

4. Pembuatan model digital X3D

- Langkah 5: Pembuatan final database dan integrasi dengan web agar dapat dipergunakan oleh masyarakat luas.

\section{Hasil Dan Pembahasan}

Data-data arsitektur nusantara diklasifikasikan sebagai berikut menurut kategori sbb:

1. Aspek amatan tipologis

2. Aspek etnis

3. Aspek sosiologis

4. Aspek Geografis

5. Aspek Kesejarahan

6. Proses ke-Kotaan

7. Aspek Arsitektonika

8. Strategi Kebudayaan dan Luhur Bangsa, yaitu: Keperkasaan Penerus Tradisi Batu Besar (misalnya Nias atau Sumba), Kewaspadaan Pelestari Hutan (misalnya Mentawai, Dayak, dan Papua), Ketekunan Penggalang Pertanian (pertanian dataran rendah dan yang di dataran tinggi seperti Tengger, Kintamani, dan sebagainya), Keterbukaan Penjalin Pesisir (misalnya Madura, Using, dan lain-lain), dan Kelenturan dan Kedinamisan Masyarakat Dagang, Industri dan Informasi 
Contoh tampilan data base adalah sbb:

1. Halaman awal

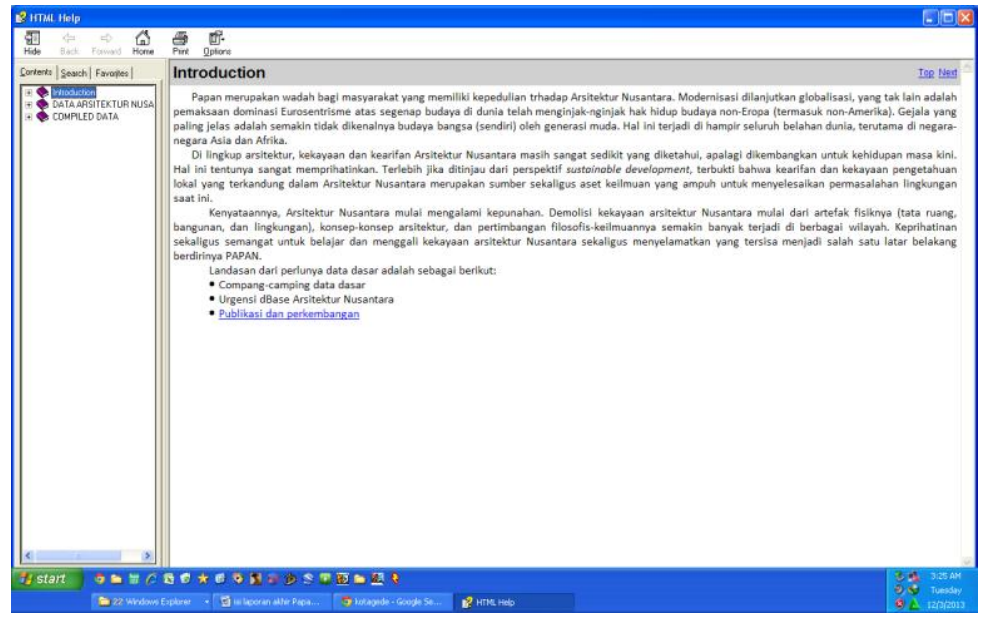

2. Setelah klik tombol 'publikasi dan perkembangan'

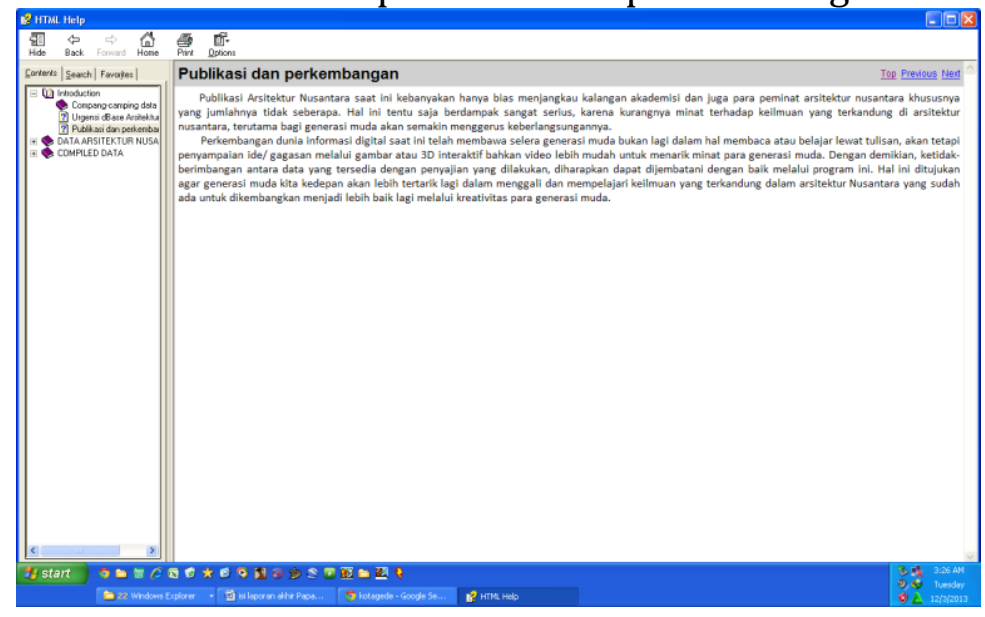

3. Menu di sebelah kiri merupakan hasil klasifikasi obyek arsitektur dan tabulasi sesuai variabel obyek amatan. Contoh tampilannya sbb:

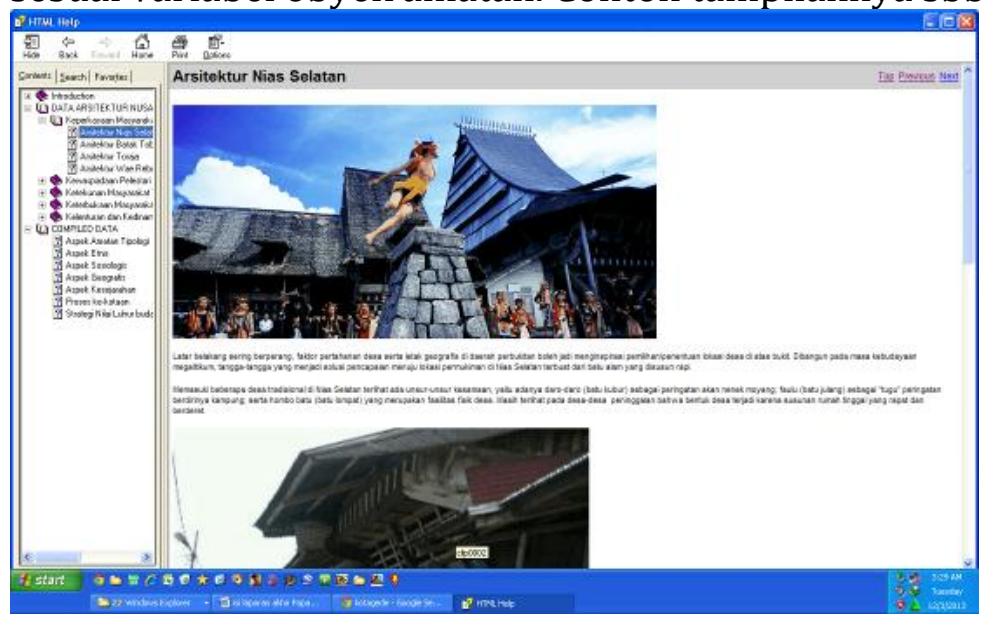



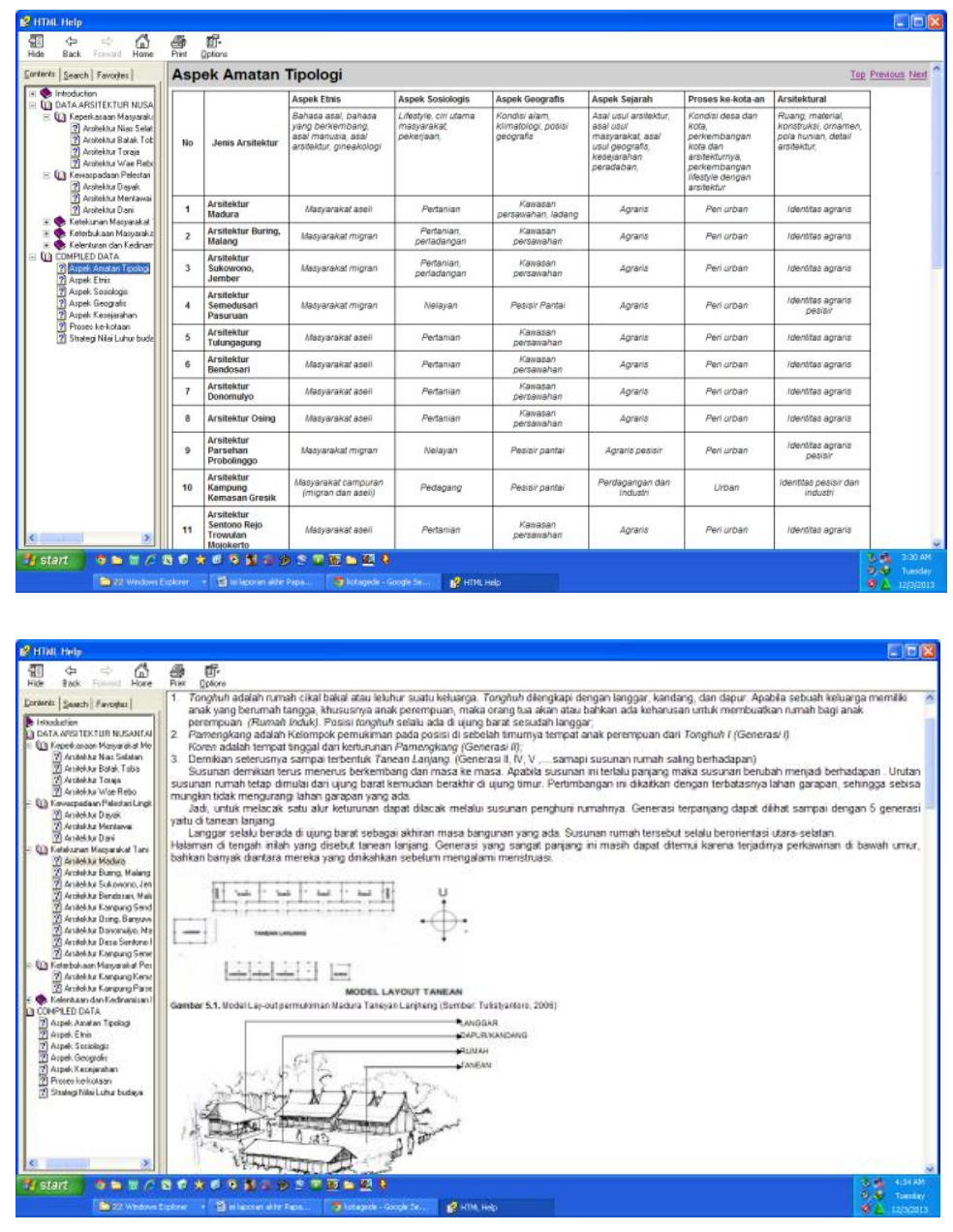

\section{Kesimpulan}

Kejamakan dan kemajemukan arsitektur nusantara dapat dikelompokkan menurut 5 kategori atau tipologi, yaitu: Keperkasaan Masyarakat Megalit, Kewaspadaan Pelestari Lingkungan Hutan, Ketekunan Masyarakat Tani, Keterbukaan Masyarakat Pesisir, dan Kelenturan dan Kedinamisan Masyarakat Dagang, Industri dan Informasi. Pemilihan kategorisasi ini didasarkan pada strategi kebudayaan yang berlandaskan pada azas persatuan. Penyusunan data base Arsitektur Nusantara dan penyebarluasannya melalui media internet merupakan strategi penyebarluasan hasilhasil penelitian terkait arsitektur nusantara agar dapat dimanfaatkan oleh berbagai kalangan secara luas. Kegiatan ini memerlukan partisipasi dari berbagai pihak secara aktif untuk terus mengembangkan, menambah, dan mengisi kelengkapannya sehingga menjadi system informasi yang lengkap dan dapat diandalkan kesahihan datanya.

Karena kejamakan dan kemajemukan arsitektur nusantara yang luar biasa besar, baik dari aspek ruang maupun waktu, maka program ini diharapkan dapat terus dikembangkan dan dilanjutkan secara partisipatif secara bersama-sama. Perbaikan dan pengembangan dapat dilakukan pada isi data base (kelengkapan informasi / data) ataupun pada struktur data base-nya. 


\section{Ucapan Terima Kasih}

Ucapan terima kasih disampaikan kepada DIKTI yang telah mendanai kegiatan ini melalui program IbM 2013 dan pihak LPPM Universitas Brawijaya yang telah memfasilitasi kegiatan ini.

\section{Daftar Pustaka}

Loekito, J. 1994. Studi Tentang Tipologi Tampak Rumah Tinggal di Kampung Surabaya pada Periode Sebelum Tahun 1942. Laporan Penelitian. Tidak dipublikasikan. Surabaya: Jurusan Teknik Arsitektur Universitas Kristen Petra,

Noor Mohammad, Bani. 2005. Model Pelestarian Berbasis Teknologi Informasi. puslit.petra.ac.id/journals/pdf.php?PublishedID=ARS04320201

Pangarsa, Galih W.P. 2007. Merah Putih Arsitektur Nusantara. Yogyakarta: Andi Offset

Habraken, N. John. 1988. Type as Social Agreement. Asian Congress of Architect. Korea: Seoul

Caniggia, Gianfranco \& Maffei, Gian Luigi. 2001. Architectural Composition and Building Typology. Alinea Editrice 